\title{
IMPLEMENTASI SUPERVISI AKADEMIK KEPALA MADRASAH DALAM MENINGKATKAN MUTUPENDIDIK DI MTs SA MIFTAHUL HIKMAH PARENGAN TUBAN
}

\author{
Siti Fatimah', Irma Rosyidah ${ }^{2}$ \\ ${ }^{12}$ Institut Agama Islam Al Hikmah Tuban \\ Email ; sitifatimah1411@gmail.com; osiyirma1105@gmail.com
}

\begin{abstract}
Activities supervision Academic are very necessary for educators, because the driving and determining factors for education outcomes are strongly influenced by the quality of the educator. Therefore, periodically the principal of madrasah needs to carry out supervision activities. The principal's duty as a supervisor is to supervise the work done by his educators. One of the supervision activities that need to be carried out by the head of madrasah is to carry out academic supervision. Through academic supervision, it is expected that the academic quality carried out by educators will incerease and have quality. Therefore, the principal of the madrasah must be able to know the achievements of his educators in carrying out the process of teaching and learning activities. The purpose of this study was to describe the implementation of academic supervision by the principal in improving the quality of teachers at MTs SA Miftahul Hikmah Parengan Tuban. The research that the authors do is included in qualitative research. In collecting data, the write used interview, observation and documentation methods. Research subjects consisted of the head madrasah and the entire teacher council in MTs SA Miftahul Hikmah Parengan Tuban.The results of the study show that the implementation of academic supervision at MTs SA Miftahul Hikmah Parengan Tuban has been running quite well, it can be seen that the implementation of ecademic supervison techiques is carried out by the principal in improving the quality educators. Supervision is carried out once every semester, there are two supervision carried out by the principal, namely academic supervision and administrative supervision. Where these two things can support in improving the quality of educator, as for the support in improving the quality of educators. Namely in the form of MGMP, education and training, seminars and workshops

Keywords : Academic supervision, Principal of madrasah, Quality of educator
\end{abstract}

\section{PENDAHULUAN}

Pendidikan merupakan faktor penting dalam perjalanan kehidupan manusia yang mempunyai sifat terus berkembang (Hasbullah,20015:7). Melalui pendidikan, suatu bangsa akan maju dan berkembang, yakni merubah berbagai sekmen kehidupan dari tingkat yang rendah, sedang menuju tingkat atau derajat kehidupan yang lebih baik (Eva Magfiroh,2014:1). Bila semakin baik pendidikanya semakin teratur dan terencana pula kehidupan yang di jalaninya. Begitu juga dalam dunia pendidikan khususnya lembaga pendidikan, perlu adanya pendidikan yang teratur dan tertata dengan benar, baik dari segi pendidikan, tenaga kependidikan, sarana prasarana, maupun kesuksesan pembelajaran yang sifatnya mendukung tercapainya pendidikan yang bermutu. Pengelolaan yang bagus dan sesuai dengan kaidah pengelolaan Lembaga Pendidikan maka Pendidikan akan berkembang dengan pesat. 
Rendahnya mutu Pendidikan di Indonesia merupakan kajian yang telah lama ada dan banyak didiskusikan oleh berbagai pihak. Tetapi permasalahan ini tetap menjadi perbincangan hangat dalam dunia pendidikan. Pasalnya Pendidikan yang berkualitas merupakan harapan semua stakeholder dan merupakan cikal bakal pengembangan bangsa. Bangsa yang baik adalah yang memiliki pemuda pemuda yang memilki kecakapan hidup yang baik, untuk mendapatkan hal tersebut maka pemerintah dan tenaga kependidikan dituntut untuk terus meningkatkan mutu pendidikan Indonesia agar dapat mengantarkan putra putri terbaik bangsa untuk tumbuh dan membesarkan bangsanya. Berbagai usaha pemerintah mengawasi jalannya pendidikan untuk meningkatkan mutu jika tidak ditindak lanjuti dengan pembinaan guru maka tidak mempunyai dampak nyata dalam kegiatan layanan di kelas. Kegiatan pembinaan ini merupakan bagian yang tidak mungkin dapat dipisahkan dalam usaha membangun dan mengembangkan mutu pembelajaran (Sutarsih dan Nurdin, 2009:311)

Undang undang guru dan dosen menyebutkan bahwa tugas utama guru adalah mendidik, mengajar, membimbing, mengarahkan, melatih, menilai, mengevaluasi peserta didik pada Pendidikan dini pada jalur formal, Pendidikan dasar dan Pendidikan menengah (UU guru dan Dosen). Oleh sebab itu, guru mempunyai tugas dan kewajiban mengembangkan dan meningkatkan kualitasnya baik dalam segi kompetensi professional, pedagogig, sosial dan kepribadian. Masalah mutu pembelajaran menyangkut masalah yang mendalam yaitu masalah kualitas mengajar yang dilakukan oleh guru harus terus mendapatkan pengawasan dan pembinaan secara berkelanjutan. Masalah ini berhubungan erat dengan kegiatan monitoring dan evaluasi yang dilakukan oleh kepala sekolah sebagai pemimpin di Lembaga melalui kegiatan supervisi.

Kepala sekolah mempunyai peran penting dalam melakukan pengawasan terhadap bagian-bagian dalam sekolah termasuk di dalamnya guru. Seorang guru professional mampu mengajar sesuai dengan cara-cara profesional. Guru profesional mampu mengajar dengan menyenangkan, memberikan motivasi motivasi, dan cakap dalam menggunakan media dan metode yang sesuai sehingga tercipta pembelajaran yang menyenangkan dan materi-materi yang diajarkan dapat dipahami sesuai dengan harapan. Untuk memenuhi harapan tersebut maka tugas kepala sekolah yaitu mengawal jalanya Pendidikan agar dapat berjalan sesuai dengan harapan. Kegiatan itu dapat dilaksanakan dengan mengadakan supervisi dan pengawasan kepada guru secara terjadwal dengan rapi dan target target yang pasti. MTS SA Miftahul Hikmah Parengan Tuban salah satu sekolah yang melaksanakan kegiatan supervisi akademik. Dalam mengimplementasikan supervisi akademik, kepala MTs SA Miftahul Hikmah mempunyai kewenangan yang besar dalam menyusun kebijakan tingkat madrasah, 
melaksanakan dan mengawasi jalannya kegiatan belajar dan mengajar agar madrasah yang dipimpin semakin memiliki kemampuan untuk mengembangkan potensi diri dan lingkungannya. Memiliki kewenangan sebagai penanggung jawab pendidikan pada tingkat madrasah, kepala madrasah kini memiliki keleluasan dalam mengembangkan, mengelola, dan mengawasi setiap program kegiatan yang dirancang, memiliki keleluasan dalam mengatur segenap sumber daya yang dimilikinya. Semua hal tersebut dilakukan agar terjadi peningkatan mutu dan produktivitas yang signifikan dalam memberi layanan belajar bermutu melalui pendidik yang profesional dan inovatif. Aktivitas pengarahan dan bimbingan dilakukan oleh kepala madrasah kepada tenaga pendidik dan personalia lainya yang langsung menangani belajar para siswa untuk memperbaiki situasi belajar mengajar inilah yang dimaksud dengan supervisi.

Berdasarkan gambaran di atas, peneliti tertarik melakukan kajian tentang pelaksanaan supervisi kepala madrasah untuk meningkatkan mutu pendidik dengan judul "Implementasi Supervisi Akademik Kepala Madrasah Dalam Meningkatkan Mutu Pendidik Di MTs SA Miftahul Hikmah" yang terangkum kedalam 3 fokus masalah yaitu Bagaimana implementasi supervisi akademik kepala madrasah dalam meningkatkan mutu pendidik MTs SA Miftahul Hikmah Parengan Tuban, bagaimana hasil implementasi supervisi akademik kepala madrasah, serta bagaimna umpan balik implementasi supervisi akademik kepala sekolah dalam meningkatkan mutu pendidik MTs SA Miftahul Hikmah.

\section{METODE}

Metode penelitian ini menggunakan pendekatan kualitatif, fenomenologis dan berbentuk deskriptif. Menurut Nana Syaodih Sukmadinata, penelitian kualitatif adalah suatu penelitian yang bertujuan untuk mendeskripsikan dan menganalisis fenomena, peristiwa, aktifitas sosial, sikap, kepercayaan, persepsi, serta pemikiran orang secara mandiri maupun kelompok (Nana Saudih Sukmadinata,2013:60). Penelitian diskriptif ini menggambarkan kinerja kepala madrasah dalam mengembangkan lembaga pendidikan Islam. Hal ini sesuai dengan pendapat Moeleong bahwa penelitian deskriptif adalah "laporan penelitiaan akan berisi kutipankutipan atau untuk memberi gambaran penyajian laporan(Lexi J Moeleong, 1992:6).

Artikel yang disusun bersifat deskriptif, karena hal ini didasarkan pada pertanyaan bagaimana. Yaitu "Bagaimana Implementasi Supervisi Akademik oleh Kepala Madrasah Dalam Meningkatkan Mutu Pendidik di Mts SA Miftahul Hikmah" secara tepat sifat sifat suatu individu, keadaan, gejala, situasi dan kondisi atau kejadian akan digambarkan secara akurat(Koentjaraningrat, 1993:19). Adapun pengumpulan data dalam penelitian ini berasal dari sumber data primer dan sekunder. Sumber data primer diperoleh melalui obervasi 
lapangan dan wawancara dengan Siti Kaspiatun Selaku kepala madrasah di MTs SA Miftahul Hikmah Sukorejo, Parengan, Tuban. Sedangkan sumber data sekunder diperoleh dari dokumentasi yakni dengan melihat keadaan lembaga dan pendidiknya secara langsung dan mengumpulkan dokumen penting Lembaga sebagai bahan penelitian

\section{HASIL DAN PEMBAHASAN}

\section{Supervisi Akademik Kepala Madrasah}

Madrasah merupakan sekolah yang berbasis agama yang sampai saat ini masih menghadapi persoalan-persoalan umum, seperti; persoalan keterbatasan sarana dan prasarana, mutu tenaga kependidikan, dan juga minimnya pendanaan. Permasalahan ini juga dihubungkan dengan penyelenggaraan supervisi pendidikan. Menurut Glickman (1981) supervisi akademik adalah serangkaian kegiatan membantu guru dalam rangka mengembangkan pengetahuannya untuk mengelola proses belajar mengajar demi tercapainya tujuan pembelajaran. Supervisi akademik merupakan upaya membantu dan membina guru meningkatkan pengetahuanya tentang proses pembelajaran guna mencapai tujuan pembelajaran (Depdiknas). Dengan demikian, esensi supervisi akademik itu sama sekali bukan menilai unjuk kerja guru dalam mengelola proses pembelajaran melainkan membantu guru mengembangkan kemampuan profesionalismenya (Depdiknas). Supervisi akademik adalah salah satu tugas pengawas madrasah yang harus dilaksanakan. Untuk melaksanakan supervisi akademik secara efektif diperlukan keterampilan konseptual, interpersonal, dan teknis. Oleh sebab itu, setiap pengawas harus menguasai konsep supervisi akademik yang meliputi: pengertian dan konsep, tujuan dan fungsi, prinsip-prinsip, dan dimensi-dimensi subtansi supervisi akademik (Kemendikbud, 2017:3).

Berdasarkan hasil penelitian di lapangan menunjukkan bahwa mutu pendidik di MTs SA miftahul Hikmah Parengan Tuban sudah baik. Terlihat dari ketersediaan keseluruhan perangkat pembelajaran baik berupa RPP, silabus maupun kesiapan dan kecakapan guru dalam penggunaan metode dan media pembelajaran. Akan tetapi, semua itu harus terus dikembangkan yakni berupa kualitas isi dari perangkat pembelajaran agar lebih dioptimalkan lagi guna meningkatkan mutu atau keprofesionalan pendidik dalam pembelajaran dan penyusunan perangkat pembelajaran. Kepala sekolah mempunyai tugas untuk selalu memberikan dukungan dan motivasi terhadap tenaga pendidiknya, dimana ini sudah menjadi tugas kepala sekolah agar terus meningkatkan kualitas pendidiknya baik berupa ketersediaan perangkat pembelajaran maupun kualitas isi perangkat pembelajaran. Hal tersebut telah dilaksanakan oleh kepala sekolah MTs SA Miftahul Hikmah, tetapi 
pelayananan tersebut harus lebih ditingkatkan dalam bentuk penyusunan program supervisi akademik yang sistematis.

Menurut kepala madrasah MTs SA Miftahul Hikmah sebagai berikut :

“Supervisi itu merupakan aktivitas membina guru yang dilakukan sesuai dengan rencana madrasah dengan harapan guru-guru disini dan seluruh staf sekolah lainya dapat melakukan pekerjaan mereka secara efektif dan efisien sesuai dengan rencana madrasah"(Wawancara, Siti Kaspiatun, 13 Pebruari 2021).

Kegiatan supervisi akademik, meliputi kegiatan merencanakan, melaksanakan dan menilai proses pembelajaran. Oleh sebab itu, sasaran supervisi akademik guru dimulai dari kegiatan perencanaan, meliputi penyiapan tersedianya perangkat pembelajaran, pelaksanaan yaitu bagaimana pelaksanaan proses pembelajaran di kelas , yang menyangkut penggunaan pemahaman guru tentang materi /srategi/metode/teknik pembelajaran, dan mengelola kelas agar tetap kondusif, kemudian kegiatan penilaian juga perlu dilakukan oleh orang yang mempunyai keahlian dalam rangka menilai hasil belajar mengajar dengan tepat sasaran. Jadi untuk melaksanakan supervisi akademik secara efektif dan efisien diperlukan ketrampilan konseptual, interpersonal, dan teknikal,

Adapun menurut ketua yayasan MTs SA Miftahul Hikmah sebagai berikut:

"Kegiatan supervisi memang sangat diperlukan untuk pendidik guna meningkatkan keprofesionalan. Bersama kepala sekolah saling bekerja sama dalam mengidentifikasi masalah atau kekurangan apa saja yang menjadi ketidakefektifannya kegiatan pembelajaran yang dilakukan oleh guru-guru dan kemudian mencari solusinya (Wawancara, Miftahul Asror, 13 Pebruari 2021).

Tujuan supervisi akademik dalam pandangan Glickman yaitu mempermudah guru dalam mengembangkan kompetensi dan kemampuan untuk mencapai tujuan pembelajaran yang telah direncanakan bagi peserta didik (Glikman, 1995). Melalui supervisi akademik diharapkan mutu akademik yang dilaksanakan guru semakin meningkat (Depdikbud, 1996 : 4). Pengembangan kompetensi/kemampuan dalam konteks ini bukan hanya ditafsirkan secara sempit, semata-mata ditekankan pada peningkatan pengetahuan dan ketrampilan mengajar guru saja, melainkan juga pada peningkatan komitmen (Commitment) atau kamauan (willingness) atau motivasi (motivation) guru, sebab dengan meningkatkan kemampuan dan motivasi kerja guru, kaualitas pembelajaran akan meningkat (Depdikbud, 1996 : 10). Guru dituntut untuk mampu mengembangkan Pendidikan yang mendorong kemajuan dengan cara merancang pembelajaran yang menyenangkan dan menarik dengan menggunakan berbagai teknologi yang ada dan terintegrasi sebagai pondasi yang kokoh dalam pembentukan karakter di era revolusi industry 4.0 dengan tujuan agar siswa selalu 
mendekatkan diri dan mengenal Tuhan-Nya (Salamah : Scaffolding Volume 02 No 1 Maret 2020)

Agar proses supervisi berjalan dengan baik, pengawas madrasah selaku supervisor harus memegang prinsip supervisi. Ngalim purwanto menjelaskan prinsip-prinsip supervisi adalah sebgai beriku:

1. Supervisi hendaknya bersifat membangun dan bersifat kreatif tidak stagnan, yaitu dibimbing dan diawasi sehingga dapat termotivasi untuk bekerja dengan giat.

2. Supervisi harus didasarkan atas keadaan riil dan dalam kenyataan yang benar (realistis, mudah dilaksanakan).

3. Supervisi harus sederhana dan mudah dalam melaksanakannya.

4. Supervisi harus dapat memberikan rasa aman pada guru-guru dan pegawai-pegawai sekolah yang disupervisi.

5. Supervisi harus didasarkan atas hubungan profesional, atas hubungan asas kerja bukan atas dasar hubungan pribadi.

6. Supervisi harus selalu selalu memperhitungkan kesanggupan, kesepakatan sikap, dan prasangka guru-guru dan pegawai.

7. Supervisi tidak bersifat mendesak (otoriter), kaku karena dapat menimbulkan perasaan gelisah atau bahkan antipati dari guru-guru.

8. Supervisi tidak boleh didasarkan kekuasaan pangkat, golongan, kedudukan atau kekuasaan pribadi.

9. Supervisi tidak dapat dilakukan dengan tergesa-gesa dan segera mengaharapkan hasil, dan tidak boleh lekas merasa kecewa.

10. Supervisi hendaknya juga bersifat preventif, korektif, dan kooperatif. Preventif berarti berusaha mencegah sekaligus menghilangkan hal yang bersifat tabu yang akan menimbulkan hal-hal yang negatif. Korektif yaitu melaksanakan perbaikan-perbaikan atas kesalahan-kesalahan yang telah diperbuat. Kooperatif berarti bahwa mencari kesalahan atau kurangan dan usaha memperbaikinya dilaksanakan secara bersama-sama oleh supervisor dan orang-orang yang diawasi (Ngalim Purwanto, 2010 : 76).

Penelitian tentang supervisi akademik ini telah banyak dilakukan oleh peneliti. Sebagai contoh yang dilakukan oleh:

1. Muhammad Haddal Yasi, "Supervisi Akademik Kepala Sekolah Dalam Meningkatkan Mutu Pembelajaran di SMA Negeri 1 Ladongi Kabupaten Koala Timur "Hasil penelitiannya menunjukan bahwa : a) program supervisi akademik kepala SMAN 1 Ladongi disusun berdasarkan hasil analisi supervisi, b) strategi pelaksanaan supervisi akademik kepala 
sekolah meliputi: melakukan supervisi perangkat pembelajaran, supervisi teknik kunjungan kelas, pengamatan terhadap kegiatan guru di kelas dan pelaksanaan tindak lanjut terhadap hasil supervisi akademik dengan bentuk pembinaan personal dan kelompok, c) implikasi supervisi akademik kepala sekolah yaitu meningkatkan kemampuan guru dalam menyusun perangkat pembelajaran, meningkatnya kemampuan guru dalam melaksanakan proses pembelajaran, meningkatnya kemampuan guru dalam mengevaluasi hasil belajar siswa (Hadal Yasin : Tesis, 2016).

2. Biner Ambarita, Paningkat Siburian, dan Sukarman Purba,"Development Of Academic Supervision Model Which Based On Education Management". Penelitian ini menyimpulkan untuk memperoleh model supervisi akademik yang paling baik meningkatkan kinerja guru secara efektif dan efisien berbasiskan karakter intruksional Indonesia. Metode penelitiannya menggunakan penelitian tindakan kelas. Hasil penelitian menunjukkan, pada siklus pertama model artistik supervisi akademik tidak ada skor kinerja guru dalam kategori baik dan siklus kedua sebanyak 86,67\% guru memiliki skor kinerja dalam kategori cukup baik, sedangkan sisanya 13,33\% guru memiliki skor kinerja dalam kategori cukup baik (Binner Ambarita : 2014, IJSBAR Volume 18 No 1).

3. Iskandar Hasan, jurnal penelitian dan pendidikan denga judul " Upaya Meningkatkan Kompetensi Guru MIPA Dalam Menyusun RPP Melalui Supervisi Akademik Di SMP Negeri 15 Kota Gorontal". Penilitian ini menyimpulkan untuk melihat efektifitas guru dalam menyusun RPP. Metode penelitian yang digunakan adalah penelitian tindakan kelas yang berlangsung selama dua siklus. Hasil penelitian menunjukan adanya peningkatan kompetensi guru dalam menyusun RPP yaitu pada siklus pertama nilai rata-rata kompetensi guru adalah 66,5\% (kategori cukup) sedangkan siklus kedua nilai rata-rata adalah 91,99\% (kategori sangat baik) (Iskandar Hasan : 2011, Jurnal Penelitian dan Pendidikan, Volume 8 Nomor 01).

Pelaksanaan supervisi oleh pimpinan Lembaga Pendidikan dalam hal ini dilakukan oleh kepala madrasah. Pelaksanaan supervisi di MTs SA Miftahul Hikmah Parengan Tuban dilaksanakan dengan dua cara yaitu : Supervisi akademik (Pembelajaran) dan Administratif. Supervisi akademik dilaksanakan dengan Teknik kunjungan kelas dengan cara melakukan observasi dikelas pada saat pelaksanaan pembelajaran berlangsung. Teknik ini dilakukan dengan tujuan untuk mendapatkan sebuah gambaran pembelajaran konkrit berupa cara guru melaksanakan pembelajaran baik pada saat menyampaikan materi, menggunakan metode dan media pada saat pembelajaran berlangsung. Supervisi akademik (pembelajaran) ini dilaksanakan setiap satu semester sekali setelah proses belajar mengajar, dari sinilah kepala 
madrasah dapat menganalisis kekurangan guru pada saat pembelajaran baik berupa model pembelajaran yang kurang bervariasi atau dari segi kurang penguasaan media yang dipakai.

Dari kekurangan tiap individu pendidik tersebut dianalisis semua yang dibutuhkan akan diarakan oleh kepala sekolah, contoh kurang penguasaan tentang pembelajaran yang sekarang ini mengunakan kurikulum K-13, dimana guru dituntut untuk mengusai media elektronik (E-Learning) diera yang semakin maju ini ditambah dengan adanya dampak covid19 yang mengharuskan siswa-siswi belajar melalui media online dan dilakukan dari rumah (Daring). Juga dimana guru sekarang ini hanya berperan menjadi fasilitator dan murid berperan aktif beda dengan pembelajaran dulu dimana guru yang menjadi pusat pembelajaran dengan metode ceramahnya. Melihat hal tersebut Kepala Madrasah MTs SA Miftahul Hikmah dalam implementasi sebagai supervisor dalam meningkatakan mutu pendidiknya, beliau mengambil langkah untuk mengikutkan para pendidiknya pelatihanpelatihan semisal MGMP (Musyawarah Guru Mata Pelajaran), diklat, seminar, workshop dan masih banyak yang lain.Strategi pelaksanaan supervisi akademik kepala MTs SA Miftahul Hikmah tersebut diatas juga telah banyak dilaksanakan di berbagai lembaga, ini menunjukkan bahwa kegiatan tersebut telah dirasakan banyak manfaatnya oleh Lembaga.

Sedangkan supervisi kepala madrasah yang berhubungan dengan administrasi, yakni pengecekan dan evaluasi dokumen yang berhubungan dengan kesiapan guru dalam mengajar, diantaranya pada saat pembelajaran online seperti yang terjadi saat penelitian ini dilakukan yaitu perencanaan jadwal pembelajaran dibuat guru bersama wakil kepala sekolah bagian kurikulum yakni jadwal pembelajaran Daring (Dalam Jaringan), Rencana Pelaksanana Pembelajaran (RPP), nilai hasil belajar dan jurnal kegiatan. Meski masih dalam masa pademi Covid-19 kegiatan supervisi tetap dilakukan, karena sebagai tugas pokok pengawasan madrasah dalam melakukan penilain dan pembinaan supervisi administrasi ini.

\section{Umpan Balik kegiatan Supervisi Kepala Madrasah terhadap peningkatan mutu Madrasah}

Kegiatan supervisi akademik merupakan kegiatan dengan tujuan akhir yakni agar guru semakin mahir dalam melakukankegiatan falisiltasi belajar bagi siswa siswanya (Depdiksnas). Dan hasil supervisi perlu ditindak lanjuti atau di evaluasi kekurangankekurangan dan kelemahan yang dialami pendidik dalam proses pembelajaran, agar memberi dampak yang bernilai untuk meningkatkan mutu pendidik, tindak lanjut tersebut bisa berupa rewardatau pelatihan capacity building. Umpan balik hasil supervisi akademik terhadap mutu pendidik ini melaui berbagai kegiatan baikbersifat langsung maupun pembinaan tidak langsung dengan melibatkan orang lain maupun Lembaga. Dari hasil wawancara bahwa 
kegiatan umpan balik ini dilakukan oleh pihak ketua yayasan dan kepala madrasah berupa pembinaan penguatan pembelajaran dan memberikan penghargaan (reward)

\section{KESIMPULAN}

Implementasi supervisi akademik di MTs SA Miftahul Hikmah ini sudah baik. diliat dari upaya yang dilakukan oleh kepala madrasah dalam melakukan supervisi kepada pendidik setiap satu semester sekali setelah melakukan kegiatan belajar mengajar berupa teknik kunjungan kelas dan observasi langsung. Kepala sekolah melakukan dua supervisi yaitu: supervisi akademik dan supervisi administrasi. Dalam rangka peningkatan mutu pendidiknya kepala madrasah juga melakukan pembinaan dan penguatan pengetahuan yaitu dengan melibatkan guru dalam kegaitan MGMP, Diklat, Worshop yang di adakan di dalam Lembaga maupun diluar Lembaga dengan tujuan untuk peningkatan mutu pembelajaran sehingga kinerja pendidik dapat terus dikembangkan sehingga pembelajaran akan berjalan secara efektif.

\section{BIBILIOGRAFI}

Ambarita Biner, Paningkat Siburian, Dan Sukarman Purba, (2014). Development Of Academic Supervision Model Which Based On Education Management, "International Journal of Sciences: Basic and Applied Research (IJSBAR), volume 18 Nomor 1

Depdiknas, (1996). Pedoman Kerja Pelaksana Supervisi, Jakarta: Depdikbud.

Eva Maghfiroh, (2014). Supervisi Pendidikan dalam Kredibilitas Tenaga Pendidikan, Jurnal Tarbiyatuna, Vol 7 No.2.

Hasbullah, (2005). Dasar-Dasar Ilmu Pendidikan,Jakarta: PT. Raja Grafindo.

Iskandar Hasan, (2011). Upaya Meningkatkan Kompetensi Guru MIPA Dalam Menyusun RPP Melalui Supervisi Akademik Di SMP Negeri 15 Kota Gorontalo, Jurnal Penelitian dan Pendidikan, Volume 8 Nomor 2

Koentjaraningrat, (1993). Metode-Metode Penelitian Masyarakat,Jakarta: PT. Gramedia.

Kemendikbud, (2017). Panduan Supervisi Akademik,Jakarta: Dirjen Dikdasmen.

LexyJMeleong, (1992). Metodologi Penelitian Kualitatif, Bandung: PT. Remaja Rosdakarya.

Muhammad Haddal Yasin, (2016). Supervisi Akademik Kepala Sekolah Dalam Meningkatkan Mutu Pembelajaran di SMA Negeri 1 Ladongi Kabupaten Koala Timur, Malang :Tesis Program Studi Manajemen Pendidikan Islam , Program Pascasarjana Universitas Islam Negeri Maulana Malik Ibrahim Malang

Nana Syaodih Sukmadinata, (2013). Metode Penelitian Pendidikan, (Bandung: PT Remaja Rosdakarya

Ngalim Purwanto, (2010). Administrasi dan Supervisi Pendidikan, Bandung: Remaja Rosdakarya 
Sutarsih, C \& Nurdin, (2009). Manajemen Pendidikan Tim Dosen Adiministrasi Pendidikan UPI, Bandung: Alfabeta.

Salamah, (2020). Peran guru PAI dalam Pembentukan karakter siswa di era Revolusi Industri 4.0 (Studi Kasus di SMAN 1 Kerici Jamabi) Scaffolding:Jurnal Pendididikan Islam dan Multikulturalisme Volumen 02 Nomor 1 Maret 2020 